Arq. Bras. Med. Vet. Zootec., v.56, n.3, p.392-397, 2004

\title{
Efeito de aditivos biológicos comerciais na silagem de capim-elefante (Pennisetum purpureum Schum)
}

\author{
[Effect of commercial biological additives on elephantgrass (Pennisetum purpureum Schum.) silage]

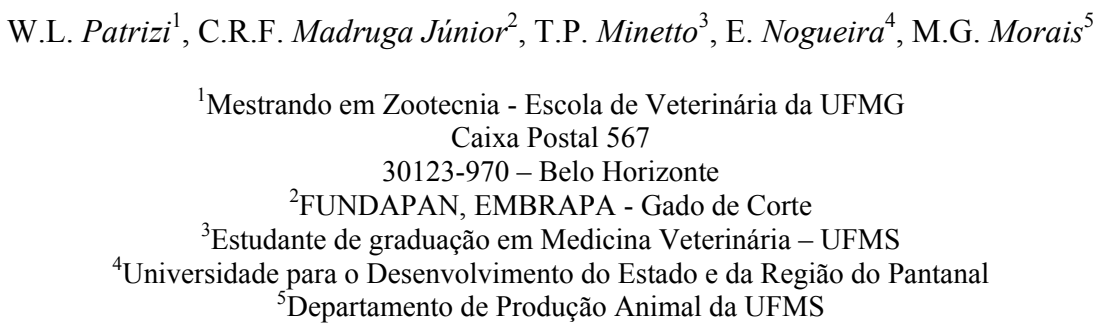

\section{RESUMO}

Avaliaram-se o pH e a composição bromatológica de silagens de capim-elefante var. Napier, sem e com três aditivos biológicos comerciais $(\mathrm{B}, \mathrm{C}$ e $\mathrm{D})$ em duas concentrações de diluição, a recomendada pelo fabricante (concentração 1) ou com o dobro (concentração 2), feitas em microsilos de PVC. O delineamento experimental foi inteiramente ao acaso, com sete tratamentos e seis repetições por tratamento. Apenas o aditivo $\mathrm{B}$ em ambas as concentrações $(3,73 ; 4,07)$ foi eficiente em reduzir $(\mathrm{P}<0,05)$ o $\mathrm{pH}$ em relação ao tratamento-controle $(5,01)$. A porcentagem de matéria seca aumentou $(\mathrm{P}<0,05)$ com o uso do aditivo B, nas concentrações $1(29,9)$ e $2(31,3)$, e dos aditivos C e D, na concentração $2(26,8$; $25,7)$. Quanto à proteína bruta, somente houve diferença $(\mathrm{P}<0,05)$ entre o tratamento-controle $(6,6)$ e os dois tratamentos com aditivo B $(13,4 ; 12,09)$. As frações de fibra em detergente neutro e lignina foram menores $(\mathrm{P}<0,05)$ nos tratamentos com aditivo $\mathrm{B}$ em relação ao tratamento-controle. A duplicação da dose do aditivo B não aumentou sua eficiência. Nos macro-elementos cálcio e fósforo das silagens, todos os aditivos elevaram a concentração de cálcio e não alteraram a de fósforo. Concluiu-se que o aditivo B, constituído de Lactobacillus plantarum e Pediococcus acidilactici, melhorou tanto a qualidade de fermentação quanto o valor nutritivo da silagem de capim-elefante, e que a duplicação da concentração dos produtos não aumentou $(\mathrm{P}<0,05)$ a qualidade das silagens.

Palavras-chave: aditivo, capim-elefante, silagem, valor nutritivo

\begin{abstract}
A completely randomized design with seven treatments and six replicates per treatment was conducted to study the effect of three commercial biological additives ( $B, C$ and $D)$, in two concentrations (manufacturer's recommended dose - concentration 1 or double dose -concentration 2) on $p H$ and chemical composition of elephantgrass (var. Napier) silage. A lower $\mathrm{pH}(P<0.05)$ was observed in silage with additive $B$ at concentrations $1(\mathrm{pH}=3.73)$ and concentration $2(\mathrm{pH}=4.07)$, when compared to the control treatment $(p H=5.01)$. Silage dry matter $(\%)$ increased $(P<0.05)$ with the use of additive $B$ at concentrations 1 and 2 (29.9\% and $31.3 \%$, respectively) and additives $C$ and $D$ at concentration 2 (26.8\% and $25.7 \%$, respectively) in comparison to the control treatment $(24.0 \%)$. Silage with additive $B$ had higher crude protein levels than the control treatment (6.6\%) at concentrations 1 (13.4\%) and 2 $(12.1 \%)$. Lignin and neutral detergent fiber levels were lower $(P<0.05)$ for treatments with additive $B$. The use of doble level of additive $B$ did not increase its efficiency. All additives increased calcium
\end{abstract}

Recebido para publicação em 20 de março de 2003

Recebido para publicação, após modificações, em 9 de dezembro de 2003

E-mail: wpatrizi@ig.com.br 
concentration, but not phosphorus concentration. These results indicated that additive $B$ (Lactobacillus plantarum and Pediococcus acidilactici) improved elephantgrass silage fermentation process and its nutritional value. Increasing commercial biological additives above the manufacturer's recommended level did not improve $(P<0.05)$ silage quality.

Keywords: additive, elephantgrass, silage, nutritional value

\section{INTRODUÇÃO}

A recente intensificação do uso de silagens na região Centro-Oeste aumentou a importância das variedades de capim-elefante. Para que uma forrageira seja conservada sob a forma de silagem é necessário o predomínio da fermentação lática sob condições de anaerobiose e vários são os fatores que podem interferir na qualidade da fermentação. Entre eles citam-se a presença de bactérias homo e heterofermentativas, o teor de carboidratos solúveis (CHO sol), os teores de umidade e de matéria seca, a compactação e a rapidez no fechamento do silo.

Uma vez estabelecida a anaerobiose, a fermentação inicia-se com a ação das bactérias que utilizam os $\mathrm{CHO}$ sol, produzindo quantidades variáveis de ácidos orgânicos como acético, propiônico, butírico e lático (McDonald, Whittenbury, 1973; Wilkinson et al., 1983; Van Soest, 1994). Simultaneamente, outras bactérias proteolíticas, principalmente as clostrídicas, podem atuar sobre as proteínas da forragem, transformando-as em nitrogênio amoniacal (N$\mathrm{NH}_{3}$ ) (Vilela, 1998), reduzindo o valor nutritivo da forragem. A ação de certas bactérias, como Lactobacillus plantarum, favorece a produção de ácido lático, um produto de alta constante de dissociação iônica e, conseqüentemente, a rápida redução do $\mathrm{pH}$ e a inibição das bactérias patógenas (grupo coliforme e Clostridium). Portanto, sendo estabelecida a fermentação lática, há diminuição das perdas de matéria seca (MS) e proteína bruta (PB), produzindo silagem com valor nutritivo $\mathrm{e}$ digestibilidade mais elevadas.

Para melhorar a qualidade de fermentação no silo tem-se aumentado o uso de inoculantes bacterianos para ensilagem. Segundo Filya et al. (2000), a maioria dos aditivos inoculantes contém cepas de bactérias homofermentativas acidoláticas (Lactobacillus plantarum, Pediococcus, Enterococcus), cuja finalidade é estimular rapidamente a fermentação lática, reduzir o $\mathrm{pH}$ e inibir a ação das bactérias indesejáveis, promovendo a desnaturação das enzimas proteolíticas (Vilela, 1998; Wilkinson, 1998).

Grande parte dos aditivos inoculantes apresenta em sua formulação uma associação de bactérias láticas e enzimas derivadas de sub-produtos microbianos. Microrganismos como os dos gêneros Bacillus e Aspergillus produzem celulases, hemicelulases, amilases, glicoamilases e proteases que podem promover a digestão de carboidratos estruturais e não estruturais como no caso do amido, produzindo açúcares solúveis utilizados como substrato para a fermentação lática. Por isso, espera-se com o uso de aditivos biológicos obter melhor qualidade da fermentação e digestibilidade dos constituintes da parede celular da forragem conservada. Trabalhos que empregam esses aditivos têm apresentado resultados contraditórios. Grise et al. (2001), ao testarem dois inoculantes comerciais, não obtiveram efeito sobre a qualidade de fermentação e sobre o valor nutritivo da silagem de milheto (Pennisetum americanum). Clavero (2001) observou aumento da MS e melhor desempenho de bezerros alimentados com silagem de capim-elefante cv Mott inoculada com bactérias acidoláticas. Entretanto, questionase a resistência dessas bactérias às temperaturas elevadas dos trópicos a que são submetidas durante o processo de ensilagem. O objetivo deste trabalho foi estudar a eficiência de adição de três aditivos biológicos disponíveis no comércio, utilizados em duas concentrações, à silagem de capim elefante var. Napier.

\section{MATERIAL E MÉTODOS}

Foram testados três aditivos biológicos comerciais aqui denominados B, C e D. O produto B continha Lactobacillus plantarum e Pediococcus acidilactici, o C, não apresentava especificação de composição e $\quad$ o $\quad$ D, 
Lactobacillus plantarum, Lactobacillus brevis, Streptococcus faecium, Pediococcus acidilactici e enzimas amilase e celulase purificadas. Para testar a eficiência foram utilizadas duas concentrações. A concentração 1 foi a recomendada pelo fabricante, e a 2 correspondeu ao dobro da quantidade e a mesma diluição em água da concentração 1 . Os produtos foram diluídos em água não clorada, de acordo com o preconizado pelo fabricante, e distribuídos em frascos plásticos com tampa do tipo nebulizadora.

$\mathrm{O}$ capim-elefante destinado à ensilagem foi colhido com aproximadamente $1,80 \mathrm{~m}$ de altura, cortado rente ao solo, e picado em ensiladeira. Devido à baixa capacidade dos microsilos para simular as condições de campo, foram preparados $100 \mathrm{~kg}$ de capim picado para cada tratamento. Foram estudados sete tratamentos designados por: $\mathrm{A}=$ capim-elefante (controle); $\mathrm{B} 1=\mathrm{A}+$ aditivo $\mathrm{B}$ na concentração $1 ; \mathrm{B} 2=\mathrm{A}+$ aditivo $\mathrm{B}$ na concentração $2 ; \mathrm{C} 1=\mathrm{A}+$ aditivo $\mathrm{C}$ na concentração $1 ; \quad \mathrm{C} 2=\mathrm{A}+$ aditivo $\mathrm{C}$ na concentração 2; $\mathrm{D} 1=\mathrm{A}+$ aditivo $\mathrm{D}$ na concentração 1; e D2=A + aditivo D na concentração 2. Foram utilizados microsilos cilíndricos de PVC proposto por Tomich et al. (1998). Após 60 dias, os microsilos foram pesados e abertos para retirada de três amostras de cada. Duas foram submetidas à pré-secagem à $56^{\circ} \mathrm{C}$ por 72 horas e a terceira foi prensada para obtenção do $\mathrm{pH}$ do suco. Nas amostras pré-secas foram feitos determinações da matéria seca (MS) a $100^{\circ} \mathrm{C}$, proteína bruta $(\mathrm{PB})$, cálcio $(\mathrm{Ca})$, fósforo $(\mathrm{P})$, fibra em detergente neutro (FDN), fibra em detergente ácido (FDA) e lignina (LIG). FDN, FDA e LIG foram analisados segundo Goering e Van Soest (1967) e os demais componentes segundo AOAC (1980), à exceção do pH, que foi medido em potenciômetro.

O delineamento experimental foi o inteiramente ao acaso, com sete tratamentos e seis repetições por tratamento, utilizando-se os procedimentos do GLM (User's... 1989). Utilizou-se o teste Dunnett a 5\% de probabilidade para comparação de médias. Para testar a eficiência de cada aditivo, foram estabelecidas equações de regressão linear, verificando a correlação entre os valores do parâmetro avaliado $(\mathrm{pH}, \mathrm{MS}, \mathrm{PB}$, FDN, FDA) com o aumento das concentrações de cada aditivo.

\section{RESULTADOS E DISCUSSÃO}

Os teores de $\mathrm{pH}, \mathrm{MS}$ e densidade são apresentados na Tab. 1. O uso do aditivo B resultou em queda do $\mathrm{pH}(\mathrm{P}<0,05)$, evidenciando que as bactérias contidas nesse produto contribuíram favoravelmente para a fermentação da silagem. $\mathrm{O}$ aditivo $\mathrm{C}$ não teve influência sobre o $\mathrm{pH}$, enquanto o aditivo $\mathrm{D}$ promoveu seu aumento, cujo efeito foi prejudicial à fermentação. Quanto às concentrações usadas, a duplicação da dose dos aditivos estudados não teve influência sobre o $\mathrm{pH}$, quando comparada à dose recomendada pelo fabricante. Considerando o pH entre 3,8 e 4,2 como indicativo de boa qualidade para silagens sem o uso de uréia (Vilela, 1998), verifica-se que somente os tratamentos B1 e B2 enquadram-se nessa classificação. Para os outros tratamentos, os valores de $\mathrm{pH}$ evidenciaram fermentação indesejável, possivelmente atribuída ao excesso de ácido acético, que propiciou lenta queda de $\mathrm{pH}$ em decorrência de sua baixa constante de dissociação iônica. Castro et al. (2001), ao trabalharem com silagem de Tifton 85 (Cynodon $s p$.), observaram maior queda no $\mathrm{pH}$ e na condutividade elétrica para os tratamentos que receberam aditivo enzimo-microbiano, sugerindo lise da membrana celular com extravasamento do conteúdo celular, proporcionando maior disponibilidade de substrato para crescimento de microrganismos. A ação eficaz das enzimas presentes nesses produtos parece ser de fundamental importância para o aumento de substrato disponível à fermentação. Condições de processamento, transporte, armazenagem e aplicação desses produtos devem ser criteriosamente seguidas, de modo a garantir sua eficiência.

A porcentagem de MS aumentou com o uso do aditivo B nas concentrações 1 e 2 e dos aditivos $\mathrm{C}$ e D na concentração 2 em relação ao tratamento sem aditivo (Tab. 1). O excesso de umidade contribui para a ocorrência de fermentações indesejáveis que acarretam perda de nutrientes solúveis ( $\mathrm{CHO}$ sol necessários à fermentação lática) da MS, por perda de efluentes ou mesmo de proteína, que se transforma em compostos tóxicos ou $\mathrm{NH}_{3}$. Vilela (1998) considera níveis de $30 \%$ ou mais de MS como adequados para a confecção de silagens de boa qualidade. Assim, somente os tratamentos B1 e B2 podem ser considerados como de boa 
qualidade quanto aos teores de MS. Clavero (2001) encontrou valores de $\mathrm{pH}$ de 4,91 e 4,11 com 18,5 e $21,8 \%$ de MS em silagens de capimelefante cv Mott com e sem aditivo enzimobacteriano, respectivamente, evidenciando prejuízo na fermentação com o uso do aditivo. Castro et al. (2001) observaram redução significativa do $\mathrm{pH}$ e aumento da $\mathrm{MS}$ quando se utilizou aditivo enzimo-bacterino em silagem de Tifton 85 . Os resultados encontrados na literatura sobre o uso desses aditivos são contraditórios, sugerindo que o produto ou seu uso inadequado pode influenciar essas características da silagem, que são importantes indicativos da qualidade de fermentação.

Tabela 1. Teores de $\mathrm{pH}$, matéria seca (MS) e densidade de silagens de capim-elefante var. Napier, tratadas com aditivos biológicos sob duas concentrações

\begin{tabular}{lccc}
\hline Tratamento & $\mathrm{pH}$ & $\begin{array}{c}\mathrm{MS} \\
(\%)\end{array}$ & $\begin{array}{c}\text { Densidade } \\
\left(\mathrm{kg} \mathrm{MN} / \mathrm{m}^{3}\right)\end{array}$ \\
\hline A (controle) & $5,01 \mathrm{a}$ & $24,00 \mathrm{a}$ & $491,74 \mathrm{a}$ \\
B1 & $3,73 \mathrm{~b}$ & $29,94 \mathrm{~b}$ & $515,33 \mathrm{a}$ \\
$\mathrm{B} 2$ & $4,07 \mathrm{~b}$ & $31,32 \mathrm{~b}$ & $517,37 \mathrm{a}$ \\
C1 & $5,01 \mathrm{a}$ & $24,83 \mathrm{a}$ & $532,47 \mathrm{a}$ \\
C2 & $5,03 \mathrm{a}$ & $26,83 \mathrm{~b}$ & $505,93 \mathrm{a}$ \\
D1 & $5,26 \mathrm{~b}$ & $24,62 \mathrm{a}$ & $595,10 \mathrm{~b}$ \\
D2 & $5,35 \mathrm{~b}$ & $25,68 \mathrm{~b}$ & $571,23 \mathrm{~b}$ \\
\hline
\end{tabular}

Médias seguidas por letras distintas na coluna diferem entre si pelo teste Dunnett $(\mathrm{P}<0,05)$.

$\mathrm{MN}=$ material natural. $\mathrm{A}=$ capim-elefante; $\mathrm{B} 1=\mathrm{A}+$ aditivo $\mathrm{B}$ na concentração $1 ; \mathrm{B} 2=\mathrm{A}+$ aditivo $\mathrm{B}$ na concentração 2 ; $\mathrm{C} 1=\mathrm{A}+$ aditivo $\mathrm{C}$ na concentração $1 ; \mathrm{C} 2=\mathrm{A}+$ aditivo $\mathrm{C}$ na concentração $2 ; \mathrm{D} 1=\mathrm{A}+$ aditivo $\mathrm{D}$ na concentração $1 ; \mathrm{D} 2=\mathrm{A}$ + aditivo D na concentração 2 .

A partir da densidade dos microsilos estimou-se a densidade média por $\mathrm{m}^{3}$ de silagem, expressa em $\mathrm{kg}$ de matéria natural $(\mathrm{MN}) / \mathrm{m}^{3}$. Por ela tem- se noção do grau de compactação e do tempo de ensilagem. As silagens dos tratamentos D1 e D2 foram mais compactadas em relação à do tratamento A. Transformando a densidade média com base na $\mathrm{MN}\left(532,73 \mathrm{~kg} \mathrm{MN} / \mathrm{m}^{3}\right)$ para densidade com base na MS (média de 26,7\%) obtém-se $142,45 \mathrm{~kg} \mathrm{MS} / \mathrm{m}^{3}$, que se situa na faixa de 100 a $150 \mathrm{~kg} \mathrm{MS} / \mathrm{m}^{3}$ de densidade registrada por Balsalore et al. (2001) para 14 empresas agropecuárias do Brasil Central, mostrando semelhança nas condições de fermentação dos micro-silos em relação às situações de campo para essa característica.

Quanto à $\mathrm{PB}$ (Tab. 2), houve diferença $(\mathrm{P}<0,05)$ entre o tratamento-controle e os tratamentos B1 e B2. Estes resultados reforçam as evidências anteriores para a eficiência do aditivo B nas duas concentrações usadas, ao elevar o conteúdo protéico das silagens. Com relação à concentração, não houve diferença quanto à $\mathrm{PB}$ com a duplicação das doses. Cheng et al. (2001) também encontraram aumento significativo da PB de silagens de capim-elefante var. Napier, com o uso de aditivo enzimático, enquanto que Grise et. al. (2001) e Clavero (2001) não obtiveram o mesmo efeito sobre a PB com o uso de dois aditivos biológicos, em cultivares de milheto e em capim-elefante cv Mott, ao usarem bactérias acidoláticas. $\mathrm{O}$ aumento da $\mathrm{PB}$ nos tratamentos B1 e B2 pode ser atribuído, em parte, à concentração mais elevada em MS, pois a melhor qualidade de fermentação observada nesse tratamento pode ter reduzido a degradação de proteína e sua conseqüente transformação em amônia (volátil).

Tabela 2. Valores de proteína bruta (PB), fibra em detergente neutro (FDN), fibra em detergente ácido (FDA), lignina (LIG), cálcio e fósforo de silagens de capim-elefante var. Napier, tratadas com aditivos biológicos sob duas concentrações

\begin{tabular}{lcccccc}
\hline Tratamento & $\begin{array}{c}\text { PB } \\
(\% \mathrm{MS})\end{array}$ & $\begin{array}{c}\text { FDN } \\
(\% \mathrm{MS})\end{array}$ & $\begin{array}{c}\text { FDA } \\
(\% \mathrm{MS})\end{array}$ & $\begin{array}{c}\text { LIG } \\
(\% \mathrm{MS})\end{array}$ & $\begin{array}{c}\text { Cálcio } \\
(\%)\end{array}$ & $\begin{array}{c}\text { Fósforo } \\
(\%)\end{array}$ \\
\hline A (controle) & $6,61 \mathrm{a}$ & $81,97 \mathrm{a}$ & $52,37 \mathrm{a}$ & $7,52 \mathrm{a}$ & $0,34 \mathrm{a}$ & 0,087 \\
B1 & $13,40 \mathrm{~b}$ & $70,73 \mathrm{~b}$ & $43,48 \mathrm{~b}$ & $6,58 \mathrm{~b}$ & $0,41 \mathrm{~b}$ & 0,083 \\
B2 & $12,09 \mathrm{~b}$ & $72,35 \mathrm{~b}$ & $42,87 \mathrm{~b}$ & $5,12 \mathrm{~b}$ & $0,44 \mathrm{~b}$ & 0,085 \\
C1 & $6,20 \mathrm{a}$ & $81,73 \mathrm{a}$ & $51,57 \mathrm{a}$ & $7,44 \mathrm{a}$ & $0,41 \mathrm{~b}$ & 0,092 \\
C2 & $6,65 \mathrm{a}$ & $81,94 \mathrm{a}$ & $50,71 \mathrm{~b}$ & $7,76 \mathrm{a}$ & $0,42 \mathrm{~b}$ & 0,083 \\
D1 & $6,92 \mathrm{a}$ & $82,28 \mathrm{a}$ & $50,82 \mathrm{~b}$ & $7,03 \mathrm{a}$ & $0,44 \mathrm{~b}$ & 0,083 \\
D2 & $7,17 \mathrm{a}$ & $82,40 \mathrm{a}$ & $50,91 \mathrm{~b}$ & $7,89 \mathrm{a}$ & $0,40 \mathrm{~b}$ & 0,082 \\
\hline
\end{tabular}

Médias seguidas por letras distintas na coluna diferem entre si pelo teste Dunnett $(\mathrm{P}<0,05)$.

$\mathrm{MS}=$ matéria seca. $\mathrm{A}=$ capim-elefante; $\mathrm{B} 1=\mathrm{A}+$ aditivo $\mathrm{B}$ na concentração $1 ; \mathrm{B} 2=\mathrm{A}+$ aditivo $\mathrm{B}$ na concentração $2 ; \mathrm{C} 1=\mathrm{A}+$ aditivo $\mathrm{C}$ na concentração $1 ; \mathrm{C} 2=\mathrm{A}+$ aditivo $\mathrm{C}$ na concentração $2 ; \mathrm{D} 1=\mathrm{A}+$ aditivo $\mathrm{D}$ na concentração $1 ; \mathrm{D} 2=\mathrm{A}+$ aditivo $\mathrm{D}$ na concentração 2 . 
Os componentes FDN, FDA, LIG, $\mathrm{Ca}$ e $\mathrm{P}$ das silagens são apresentados na Tab. 2. A fração de FDN foi menor $(\mathrm{P}<0,05)$ nos tratamentos $\mathrm{B} 1 \mathrm{e}$ B2 em relação ao tratamento-controle. A duplicação da dose do aditivo B não aumentou sua eficiência. Os aditivos $\mathrm{C}$ e $\mathrm{D}$ não foram eficientes em diminuir a FDN. A fração de FDA foi menor $(\mathrm{P}<0,05)$ nos tratamentos $\mathrm{B} 1, \mathrm{~B} 2, \mathrm{C} 2$, D1 e D2. O aditivo B foi mais eficiente em reduzir essa fração que contém componentes mais indigestíveis. Na concentração 2, a redução na FDA, quando ocorreu, foi pouco expressiva. Em relação ao teor de lignina, que é indigestível, somente os tratamentos B2 e B1 apresentaram valores menores. Associando padrões de fermentação ( $\mathrm{pH}$ e MS) e valor nutritivo (PB, FDN, FDA e LIG), as silagens contendo o aditivo $\mathrm{B}$, possivelmente, apresentariam maior potencial de digestibilidade.

Clavero (2001) encontrou teores de 65,3\% e $40,2 \%$ para a FDN e FDA, respectivamente, em silagens de capim-elefante cv Mott sem aditivo e $61,8 \%$ e $37,8 \%$ em silagens com bactérias acidoláticas, valores inferiores aos deste estudo. Essa diferença pode ser justificada pela idade do cultivar Mott, 42 dias de rebrote, enquanto que o cultivar Napier foi usado com idade mais avançada. Cheng et al. (2001), em silagem de capim-elefante var. Napier com 63 dias de crescimento, registraram valor de $74,0 \%$ de FDN. Nos tratamentos com inoculante bacteriano os resultados foram 69,6 e $45,4 \%$ para FDN e FDA. As reduções da FDN e FDA podem indicar a ação de enzimas sobre os carboidratos da parede celular, podendo aumentar a disponibilidade de substrato para as bactérias. $\mathrm{Na}$ literatura não foram encontradas referências quanto à fração de lignina em silagens.

Quanto aos macro-elementos Ca e P das silagens, todos os aditivos elevaram a concentração de cálcio, mas não alteraram a de fósforo. Estes resultados contrastam, parcialmente, com os de Maesta et al. (2000), que ao utilizarem o aditivo denominado acipin em silagem de capimelefante, não observaram melhora nos teores de $\mathrm{Ca}$ e P. Valadares Filho (2000), na silagem de capim-elefante, encontrou teor de $0,28 \%$ de Ca e $0,10 \%$ de $\mathrm{P}$, isto é, valor mais baixo em $\mathrm{Ca}$ e equivalente em P. Estudos sobre a ação de aditivos enzimo-bacterianos sobre esses minerais são escassos e de difícil comparação devido à grande variação de concentração deles no solo.

As regressões lineares obtidas para as variáveis $\mathrm{pH}, \mathrm{MS}, \mathrm{PB}, \mathrm{FDN}$ e FDA em relação à concentração do aditivo utilizado são apresentados na Tab. 3. Elas mostram como se comportaria cada variável conforme o nível de inclusão de aditivo. $\mathrm{Na}$ regressão linear para $\mathrm{pH}$ com aditivo $\mathrm{B}$, por exemplo, o valor da variável sem aditivo seria de 4,7, aproximadamente, e para cada nível de inclusão do aditivo haveria redução de, aproximadamente, 0,47. Os coeficientes de determinação foram, em geral, baixos, indicando que o poder de representação dessas regressões frente à variação total observada é limitada, e que, possivelmente, as variáveis estudadas não se comportam de maneira linear.

Tabela 3. Regressão linear obtida para cada tipo de aditivo para as variáveis $\mathrm{pH}$, matéria seca (MS), proteína bruta (PB), fibra em detergente neutro (FDN) e fibra em detergente ácido (FDA) segundo o aditivo e a concentração usada

\begin{tabular}{lcccc}
\hline Aditivo & $\begin{array}{c}\text { Variável } \\
(\mathrm{Y})\end{array}$ & Regressão & $\begin{array}{c}\text { Coeficiente de } \\
\text { determinação }\end{array}$ & $\begin{array}{c}\text { Nível de } \\
\text { significância }\end{array}$ \\
\hline B & pH & $\mathrm{Y}=4,7378-0,4683 \times$ & $\mathrm{R}^{2}=0,42$ & $\mathrm{P}<0,01$ \\
B & MS & $\mathrm{Y}=24,8781+3,5885 \times$ & $\mathrm{R}^{2}=0,80$ & $\mathrm{P}<0,01$ \\
B & PB & $\mathrm{Y}=7,9583+2,7400 \times$ & $\mathrm{R}^{2}=0,56$ & $\mathrm{P}<0,01$ \\
B & FDN & $\mathrm{Y}=79,8267-4,8117 \times$ & $\mathrm{R}^{2}=0,60$ & $\mathrm{P}<0,01$ \\
B & FDA & $\mathrm{Y}=50,9850-4,7467 \times$ & $\mathrm{R}^{2}=0,77$ & $\mathrm{P}<0,01$ \\
C & MS & $\mathrm{Y}=23,7726+1,4331 \times$ & $\mathrm{R}^{2}=0,77$ & $\mathrm{P}<0,01$ \\
C & FDA & $\mathrm{Y}=52,3789-0,8300 \times$ & $\mathrm{R}^{2}=0,31$ & $\mathrm{P}<0,05$ \\
D & MS & $\mathrm{Y}=23,9116+0,8507 \times$ & $\mathrm{R}^{2}=0,52$ & $\mathrm{P}<0,01$ \\
D & PB & $\mathrm{Y}=6,6219+0,2775 \times$ & $\mathrm{R}^{2}=0,22$ & $\mathrm{P}<0,05$ \\
D & FDA & $\mathrm{Y}=52,0936-0,7292 \times$ & $\mathrm{R}^{2}=0,24$ & $\mathrm{P}<0,05$ \\
\hline $\mathrm{x}=$ concentração utilizanda
\end{tabular}




\section{CONCLUSÕES}

Nas condições deste trabalho somente o aditivo $\mathrm{B}$, associação de Lactobacillus plantarum e Pediococcus acidilactici, foi eficiente para as variáveis relativas à fermentação e ao valor nutritivo das silagens de capim-elefante var. Napier. Não houve vantagem em dobrar a concentração indicada dos aditivos pelo fabricante para aumentar a eficiência de fermentação.

\section{REFERÊNCIAS BIBLIOGRÁFICAS}

BALSALORE, M.A.A.; NUSSIO, L.G.; MARTHA JÚNIOR, G.B. Controle de perdas na produção de silagens de gramíneas tropicais. In: MATTOS, W.R.S. A produção animal na visão dos brasileiros. Piracicaba: FEALQ, 2001. p.890-911.

CASTRO, F.G.F.; NUSSIO, L.G. Parâmetros físicoquímicos da silagem de tifton 85 (cynodon sp.) sob efeito do pré-emurchecimento e de inoculante bacterianoenzimático. In: REUNIÃO ANUAL DA SOCIEDADE BRASILEIRA DE ZOOTECNIA, 38., 2001, Piracicaba. Anais... Piracicaba: SBZ, 2001. 4p. (CD)

CHENG, Y.K.; CHEN, C.S.; PENG, P.W. Effects of different additives on silage quality of napiergrass. In: INTERNATIONAL GRASSLAND CONGRESS, 19., 2001, São Paulo. Proceedings... São Paulo: BSAH, 2001. p.771-772.

CLAVERO, T. Quality and nutritive value of Mott dwarf elephantgrass silage with biological additives. In: INTERNATIONAL GRASSLAND CONGRESS, 19., 2001, São Paulo. Proceedings... São Paulo: BSAH, 2001. p.770-771.

FILYA, I.; ASHBELL, G.; HEN, Y. et al. The effect of bacterial inoculants on the fermentation and aerobic stability of whole crop wheat silage. Anim. Feed Sci. Technol., v.88, p.39-46, 2000.

GOERING, H.K.; VAN SOEST, P.J. Forage fiber analysis. Handbook n.379, Agricultural Research Service, USDA, Washington, DC, 1970.

GRISE, M.M.; JOBIM, C.C.; CECATO, U. et. al. Efeito do uso de inoculantes na composição química e
$\mathrm{pH}$ da silagem de milheto (P. americanum (L.) Leeke). In: REUNIÃO ANUAL DA SOCIEDADE BRASILEIRA DE ZOOTECNIA, 38., 2001, Piracicaba. Anais... Piracicaba: SBZ, 2001. 3p. (CD)

MAESTÁ, S.A.; VASQUEZ, H.M.; COELHO DA SILVA, J.F. Silagem de capim-elefante (Pennisetum purpureum, Schum) com e sem acipin, associada a duas fontes nitrogenadas na alimentação de bovinos em confinamento. In: REUNIÃO ANUAL DA SOCIEDADE BRASILEIRA DE ZOOTECNIA, 37., 2000, Viçosa. Anais...Viçosa: SBZ, 2000. (CD).

McDONALD, P.; WHITTENBURY, R. The silage process. In: BUTTLER, G.W. (Ed.). Chemistry and biochemistry of herbage. London: Academic, 1973. v.3, p.33-60.

OFFICIAL methods of analysis. 13.ed. Washington: AOAC, 1980. 1018p.

TOMICH, T.R.; GONÇALVES, L.C.; RODRIGUES, J.A.S. et al. Comparação de três tipos de silos experimentais para avaliação de silagens. In: REUNIÃO ANUAL DA SOCIEDADE BRASILEIRA DE ZOOTECNIA, 35., 1998, Botucatu. Anais... Botucatu: SBZ, 1998. 3p. (CD)

USER'S guide: statistics. Cary: SAS Institute, 1989.

VALADARES FILHO, S.C. Nutrição, avaliação de alimentos e tabelas de composição de alimentos para bovinos. In: REUNIÃO ANUAL DA SOCIEDADE BRASILEIRA DE ZOOTECNIA, 37., 2000, Viçosa. Anais...Viçosa: SBZ, 2000. p.267-337

VAN SOEST, P.J. Nutritional ecology of the ruminant. 2.ed. Ithaca: Cornell University, 1994. 476p.

VAN SOEST, P.J. Nutritional ecology of the ruminant. Ithaca: Cornell University, 1982. 373p.

VILELA, D. Aditivos para silagem de plantas de clima tropical. In: REUNIÃO DA SOCIEDADE BRASILEIRA DE ZOOTECNIA, 35., 1998, Botucatu. Anais... Botucatu: SBZ, 1998. p. 73-108.

WILKINSON, J.M. Additives for ensiled temperate forage crops. In: REUNIÃO DA SOCIEDADE BRASILEIRA DE ZOOTECNIA, 35, 1998, Botucatu. Anais... Botucatu: SBZ, 1998, p. 53-72.

WILKINSON, J.M. Valor alimentício de las forrageiras ensiladas de clima tropical y templado. Rev. Mundial Zootec., n.46, p.35-40, 1983. 